\title{
“MITO” Y „LEYENDA” DE EVA PERÓN. UNA APROXIMACIÓN A TRAVÉS DE SUS DISCURSOS
}

\author{
María de Monserrat Llairó \\ Facultad de Ciencias Económicas \\ de la Universidad de Buenos Aires, Argentina \\ email: mmlairo@gmail.com \\ Boris Matías Grinchpun \\ Facultad de Ciencias Económicas \\ de la Universidad de Buenos Aires, Argentina \\ e-mail: matiasgrinchpun@gmail.com
}

\begin{abstract}
Resumen: Eva Perón ha adquirido una fama notable a lo largo de las décadas. De personaje político clave y símbolo partidario, „Evita” ha pasado a convertirse en uno de los artefactos culturales más estrechamente asociados con la Argentina a nivel mundial. En ese país tanto la „Dama de la Esperanza" como el movimiento al que perteneció continúan siendo materia de disputa historiográfico y, de manera no menor, un tópico recurrente en debates sociales y políticos todavía abiertos. Este artículo pretende comprender mejor la singular deriva de Eva Perón en el plano discursivo y simbólico a través de un análisis de las imágenes configuradas al calor de esos debates. Finalmente, se ofrecerá dar una nueva mirada sobre esas discusiones y sobre la notoriedad alcanzada por Eva Perón a partir de las ambiguas tramas desplegadas en sus alocuiones públicas, donde liberación femenina, valores familiares tradicionales y verticalidad se conjugaban de forma inestable.
\end{abstract}

Palabras Clave: Eva Perón, peronismo, Argentina, historia cultural.

\section{INTRODUCCIÓN. ¿UNA VOZ DEL PASADO?}

La relevancia adquirida por Eva Perón hace superflua, en buena medida, cualquier introducción. Los puntos más importantes de su biografía seguramente son lo suficientemente conocidos como para poder pasar directamente del plano de la exposición y la descripción al de la reflexión y el comentario. ¿O es necesario siquiera este paso? ¿Hay que seguir agregando glosas y epígrafes a este personaje? ¿No habla su vida por sí sola? Durante los fugaces seis años que pasó como primera dama de la Argentina, emprendió iniciativas sociales y reformas 
políticas que tendrían un impacto duradero en la historia de su país. Sus proyectos adquirieron relevancia al punto de darle visibilidad internacional, algo inusitado para la esposa de un mandatario latinoamericano. Sin embargo, esta visión pretendidamente „realista” y „empírica” omite que las biografías no son construcciones objetivas (si es que existe algo de este estilo). La de Eva Perón no sería la excepción, ya que la figura que se representa en esos relatos es construida a partir de polémicas, y cualquier comparación entre dos versiones muestra que nada de imparcial y autoevidente hay en esa historia.

Por empezar, ella pertenece a un pasado abierto: la perdurabilidad del peronismo le confiere a sus discursos un barniz de actualidad. „Evita” se ha transformado en uno de los símbolos centrales de ese movimiento político, así como en un blanco predilecto de sus opositores. Quien se aproxime a esta figura debería tal vez recordar, como sostenía el filósofo italiano Benedetto Croce, que toda historia es en definitiva una historia contemporánea, en tanto las preguntas se hacen desde un presente que motiva la reflexión (Croce 1942: 16). ${ }^{1}$ Discutir sobre Eva Perón, como discutir sobre la corriente que su marido fundó, implica referirse a cuestiones importantes de la historia argentina de las últimas décadas y a debates todavía no resueltos.

Las reflexiones no deberían limitarse al contexto argentino, ya que su popularidad fuera del país en que vivió y actuó amerita ser explicada. Podría pensarse, en primera instancia, que Eva Perón puede aparecer como parte de un amplio movimiento de reforma política, mejora social y emancipación femenina que se habría producido, a distintos ritmos y a través de diversos caminos, a lo largo del siglo XX y que todavía continúa. Siguiendo el consenso historiográfico construido en las últimas décadas, el peronismo podría ser considerado como una expresión contradictoria y limitada de ese proceso de cambio, y habría tenido en Eva a una de sus principales abanderadas (Belini y Korol 2012: 115-154; Gené 2008; Milanesio 2014; Rapoport 2012; Torre 2002). Incluso podría argumentarse que el atractivo reside en que muchos de los objetivos planteados por ella permanecen incumplidos, razón por la cual los llamados de hace setenta años a una distribución más justa del ingreso, a una legislación más favorable a la clase trabajadora y a un rol más activo del Estado y la comunidad en el cuidado de los sectores más vulnerables, suenan todavía muy cercanos.

1 "Los requerimientos prácticos que laten bajo cada juicio histórico, dan a toda la historia el carácter de 'historia contemporánea' por lejanos en el tiempo que puedan parecer los hechos por ella referidos; la historia, en realidad, está en relación con las necesidades actuales y la situación presente en que vibran aquellos hechos". 


\section{LAS CARAS DE EVA}

Las tramas del discurso social en la Argentina han favorecido la aparición de diversas imágenes de Eva Perón, incluso mientras ella vivía. ${ }^{2}$ Estas representaciones aparecen como formas particulares de concebir al personaje de acuerdo con los sentimientos, deseos e intereses de grupos sociales y políticos que los construyen, aunque ésta no es una operación siempre consciente. Estas formas, que por conveniencia serán denominadas „visiones”, no son instrumentos dóciles en las manos de sus creadores, sino que por el contrario se autonomizan rápidamente y adquieren formas insospechadas.

Una de esas visiones es la de „Evita”, sobrenombre que se le otorgó a la primera dama desde los comienzos de su carrera y que ella asumió con orgullo. Como afirmaba en una de sus frecuentes presentaciones, „la compañera Evita -como siempre digo- ha preferido ser, antes que la esposa del presidente de la Argentina, la compañera Evita, si ese Evita es dicho para calmar un dolor en algún hogar del país" (Perón 2012: 291). ${ }^{3}$ Desde este punto de vista, Eva era el „amparo de los humildes”, es decir de todos aquellos sectores sociales olvidados y pisoteados por un otro conceptuado como „oligarquía explotadora”. Pero la „dama de la esperanza” veía su accionar y sus propias palabras como agentes de transformación, factores de una taumaturgia social y política: así como Eva Duarte se había transformado en „Evita”, se planteaba que los „descamisados” habían adquirido consciencia de su dignidad y derechos para convertirse en „los trabajadores argentinos” y „el pueblo de Perón” (Perón 2012: 293).

Podría plantearse que esta visión eleva a „Evita” a la categoría de mito. Mito alimentado por los recuerdos de quienes conocieron la acción de la Fundación de Ayuda Social, los Torneos Infantiles y los hogares de tránsito, así como por la propaganda realizada por el peronismo durante décadas (Plotkin 2013). ${ }^{4}$ Actualmente, esta concepción puede encontrarse dentro de las distintas fracciones del peronismo, como uno de los pocos elementos que unifica e identifica a un movimiento tan fragmentario y dispar. Pero también excede las fronteras partidarias, ya que „Evita” encuentra adeptos en regiones insospechadas del espectro político, como la extrema derecha nacionalista y el „progresismo" de centro-izquierda.

La contracara de la celebración y la admiración es el desprecio y la condena. „Evita” se convierte en una de las expresiones más cabales de la intolerancia

2 "El discurso social: todo lo que se dice y se escribe en un estado de sociedad, todo lo que se imprime, lo que se habla públicamente o se representa hoy en los medios electrónicos [...] O más bien podemos llamar 'discurso social' no a ese todo empírico, cacofónico y redundante, sino a los sistemas genéricos, los repertorios tópicos, las reglas de encadenamiento de enunciados que, en una sociedad dada, organizan lo decible -lo narrable y opinable- y aseguran la división del trabajo discursivo" (Angenot 2010: 21).

3 Discurso pronunciado el 14 de octubre de 1948, en la ciudad de Mar del Plata, al público reunido en Plaza Luro.

4 Sobre la propaganda y la "mitología" del peronismo, ver 
característica de un régimen y una ideología autoritarios. Este contrarrelato se alimenta de algunas de las diatribas más incendiarias de la primera dama:

Pero hoy como ayer, mis queridos descamisados, esas fuerzas de la antipatria, esas fuerzas de la negación, esas fuerzas de la demagogia, esas fuerzas contrarias a nuestra unidad y a nuestro porvenir nos encuentran aquí, vigilantes y de pie, junto al Lider y definitivamente unificados alrededor de él, para decirles que somos dueños de nuestros destinos y que iofrecemos nuestras vidas por la Patria y por Perón! (Perón 2012: 295). ${ }^{5}$

Los ataques a los „vendepatrias”, que podían incluir llamados a cobrarse justicia por mano propia, demostrarían la esencia violenta y antidemocrática del peronismo (Romero 1959: 227-256; Finchelstein 2008: 97-129). Para las perspectivas más afines al conservadurismo político y el liberalismo económico, la asistencia social y la legislación laboral habrían sido algunas de las medidas que distorsionaron el „normal funcionamiento" de la economía y crearon demandas „exageradas” en los sectores populares (Díaz Alejandro 2002; Llach y Gerchunoff 2003). Para los autores más cercanos al socialismo reformista y la izquierda, el objetivo de los gobiernos peronistas no habría sido erradicar la pobreza sino cooptar a las clases más vulnerables y manipulables. El objetivo no habría la cacareada „dignificación”, sino un disciplinamiento que garantizara la obediencia al Partido Justicialista. Los argumentos han llegado al punto un tanto grotesco de apuntar a la imponente colección privada de vestidos y joyas de Eva Perón como una prueba palpable de su falta de sinceridad hacia los carenciados. ${ }^{6}$

Esta „leyenda negra” ha sido construida y cultivada por los múltiples opositores al peronismo. Como era de esperarse, la importancia de esta figura dentro de la historia y la mitología de ese movimiento la convirtió en un blanco irresistible e ineludible para los críticos. En cierta forma, esta representación es simbiótica con el mito de „la dama de la esperanza”: la oposición entre ambas potencia un debate en el cual se buscaría en última instancia comprender el sentido y significado de Eva y del movimiento que lideró. Hasta podría plantearse que admiradores y detractores serían „rivales cómplices”, en tanto lucharían sin poner en discusión la importancia del personaje y del movimiento político al que perteneció como factor clave para explicar lo que para unos es el factor principal de la „decadencia” del país mientras que para otros es, por el contrario, la clave para erradicar su atraso.

Los pasionales embates de Evita contra la „oligarquía” fueron también rescatados por grupos que creían haber encontrado en ella a una rebelde. Las aristas antimperialistas y populares de sus discursos resultaron así susceptibles de una relectura desde la izquierda más revolucionaria:

5 Discurso pronunciado el 17 de octubre de 1948, ante el pueblo reunido en Plaza de Mayo, con motivo de celebrarse el "Día de la Lealtad".

${ }^{6}$ El guardarropas y las alhajas de Eva Perón fue exhibidos con gran fanfarria por la "Revolución Libertadora". 
La obra del General Perón es demasiado grande para que la comprendan todos. Únicamente el pueblo la comprende, porque el pueblo mantiene intactos los valores morales que nos legaron los grandes de nuestra patria. [...]

La obra del General Perón en favor de la clase trabajadora, en pos de la libertad económica y de la soberanía de nuestra Patria, es demasiado grande para que la comprendan los espíritus mediocres y mezquinos (Perón 2012: 29).7

Algunos teóricos intentaron ver en este tipo de expresiones las semillas de un peronismo revolucionario (Altamirano 2011; Anguita y Caparrós 2015; Gillespie 2008). Para muchos grupos políticos y organizaciones armadas surgidos durante los años ,60 y ,70, invocar el legado de Evita y el justicialismo era una estrategia excelente para legitimarse frente a las masas. Incluso llegaron a plantear que, de haber sobrevivido a su enfermedad, ella habría eliminado a los elementos conservadores del movimiento para transformarlo en el frente de liberación nacional y social que estaba destinado a ser. De todas maneras, la sinceridad de esta devoción por la primera dama es una cuestión que permanece abierta al debate.

Se ha pensado también en la Evita feminista. Feminista, en primer lugar, por su propia experiencia: de actriz menor se transformó en primera dama, bregó por el voto femenino, tuvo un rol protagónico en la política de asistencia social y lideró el Partido Peronista Femenino. Feminista, en segundo lugar, por su legado: la ley de voto femenino cambió el rol político de la mujer en Argentina y tendría un rol central en las transformaciones de la Argentina. De hecho, Eva interpeló directamente esa „la mujer argentina”, construyéndola como un actor social políticamente consciente y en igualdad de condiciones no sólo para elegir a sus representantes:

Creo que, día a día, aqui y allá, en las fábricas, o en los surcos, en los hogares o en las aulas, se acrecienta esa fuerza de atracción que nos reúne en un inmenso bloque de mujeres, con iguales aspiraciones y parejas inquietudes. Creo que, al fin, hemos adquirido el claro concepto de que no estamos solas, ni aisladas, sino, por el contrario, solidarias y unidas alrededor de una bandera común de combate.

(Perón 2012: 45). ${ }^{8}$

Estos ejemplos no agotan el inmenso caudal de visiones que se han construido sobre esta figura. El paso del tiempo ha generado nuevas perspectivas y ha transformado algunas de las ya establecidas. Entre el rechazo absoluto y la idolatría, puede encontrarse un amplio abanico de representaciones. Esto reafirma la importancia adquirida por Eva y resalta la dificultad de elaborar un texto comprensivo.

7 Discurso pronunciado el $1^{\circ}$ de mayo de 1949, con motivo de la celebración del Día del Trabajo, en Plaza de Mayo.

8 Mensaje pronunciado el 27 de enero de 1947, dedicado a la Mujer Argentina, por L.R.A. Radio del Estado y la Red Argentina de Radiodifusión. 
Por ese motivo, este artículo no pretende ofrecer un compendio exhaustivo de estas „visiones” ni juzgar la veracidad de cada una. De hecho, Eva no sería un rompecabezas a ser construido a partir de una sumatoria de perspectivas encontradas. A lo que se apunta, por el contrario, es a ver el proceso por el cual Eva habría sido „descompuesta” en esta múltiples visiones a partir de las ambiguas tramas discursivas puestas en juego en sus alocuciones públicas.

\section{MEMORIAS DE MUNDOS DESAPARECIDOS ${ }^{9}$}

Una forma interesante de abordar esos es tomando en consideración la concepción del tiempo que presentan. El peronismo se pensaba a sí mismo como un movimiento revolucionario, por lo cual planteaba su aparición como un corte en el desarrollo histórico. A partir de ahí, nacían una sociedad y un tiempo nuevos. ${ }^{10}$ Previamente, la Argentina se habría caracterizado por:

En lo social, el abandono total de la justicia, con el enquistamiento de los privilegios y la explotación del trabajador. En lo político, con la sistematización del fraude en favor de los partidos que se turnaban en el gobierno o se lo quitaban mutuamente según el menor o mayor apoyo de los intereses en juego; y en lo económico, el entreguismo y la venta del país.

(Perón 2012: 134). ${ }^{11}$

El 17 de octubre habría puesto fin a la era de oscuridad: en esa "hora decisiva" los trabajadores "jugaron su vida para que triunfara la justicia" y "rescataron al Coronel de las garras del odio" (Perón 2012: 132). A partir de entonces, el conflicto de clases habría dado paso a la armonía y la colaboración entre pueblo y Estado:

Quiero ahora destacar la enorme satisfacción que me produce auscultar esta perfecta unidad entre el pueblo y el General Perón, hecho nuevo que también tiene su origen en el 17 de octubre. Movidos, dinamizados por idénticos anhelos y las mismas aspiraciones, el pueblo y su Lider forman hoy una unidad indestructible, que consolida y ensancha el camino del movimiento peronista. De nada valdrá, entonces, el mezquino retaceo de los rezagados y los resentidos.

(Perón 2012: 134-135). ${ }^{12}$

9 Este subtítulo es una referencia a la traducción castellana de las Memoires d'un révolutionnaire, 1901-1941 de Victor Serge.

${ }^{10}$ Roger Griffin ha analizado la "sensación" de un nuevo comienzo bajo los regímenes de Benito Mussolini y Adolf Hitler en su estudio las relaciones complejas y ambiguas entre fascismo y modernismo (Griffin 2007).

${ }^{11}$ Discurso del 17 de octubre de 1949.

${ }^{12}$ Discurso del 17 de octubre de 1949. 
Eva Perón habría pretendido también reinterpretar toda la historia argentina a partir del surgimiento del peronismo. Los ideales de los „Padres Fundadores” Manuel Belgrano y José de San Martín habrían sido olvidados por generaciones de políticos corruptos y oligarcas codiciosos. Fue necesaria la llegada de un líder popular para que esos valores, los únicos auténticamente nacionales, fueran rescatados. A partir de entonces, los conflictos políticos habrían dado paso a la unidad, la mezquindad a la solidaridad, la lucha a la colaboración de clases. Como en los grandes relatos construidos a partir de la idea de progreso histórico, el peronismo cree en la posibilidad de transformar gradualmente a la sociedad y al hombre para vencer los problemas del presente.

De todas maneras, la amenaza de sectores "rezagados" que quieran regresar a etapas anteriores se encuentra siempre latente. La existencia de ese enemigo le permite al peronismo construirse a sí mismo como un movimiento con rasgos militares:

\begin{abstract}
Ser peronista significa unidad, comprensión, una mutua tolerancia. Unidos venceremos, divididos no tendremos derecho a estar al lado del General Perón. Todos los peronistas tenemos una inmensa responsabilidad. No tanto por nosotros, sino por todos los compañeros descamisados que representamos. La responsabilidad de apoyar incondicionalmente al General Perón; la de allanar todas las dificultades en pro de una unidad peronista.
\end{abstract}

(Perón 2012: 96).13

Eva Perón exaltó una y otra vez a la disciplina, la unidad y la obediencia como cualidades fundamentales del militante peronista. Si la oportunidad histórica es irrepetible, entonces no hay lugar para los débiles ni los indecisos. De hecho, Eva se habría autoimpuesto esos valores para servir de modelo a los descamisados. Esta lectura épica y heroica del peronismo apunta a una cuestión incómoda: ¿no podría atribuirse a esa entrega cercana al faccionalismo las dificultades que el peronismo ha tenido para relacionarse con las fuerzas de oposición? La perspectiva de „amigo-enemigo” presentada por Eva Perón, para retomar el célebre binomio de Carl Schmitt, ¿no se mantiene en cierta medida hasta la actualidad en los peronistas de las nuevas generaciones?

La concepción binaria aparece también cuando Eva hace referencia a la estructura de las sociedades modernas. Las diferencias entre ricos y pobres, oligarquía y trabajadores, burguesía y descamisados, son un lugar común en sus discursos. Sin embargo, su solución no es combativa: el objetivo es superar esa división al unir a unos y otros en "el pueblo".

${ }^{13}$ Discurso pronunciado el 27 de julio de 1949, ante los delegados a la reunión nacional del Partido Peronista en Parque Norte. Respecto de la militarización y politización del lenguaje, continúa resultado sugestivo el valioso "estudio de campo" del filólogo judío Víctor Klemperer en el Tercer Reich. 
El pueblo no es una simple clase social. Este sería un simple concepto económico. No se puede decir, por ejemplo, que sea la clase de los pobres. El pueblo mismo sabe que aunque en su seno la pobreza es lo habitual, no todos son pobres en el pueblo [...] y que así como hay ricos, aunque muy pocos, que lo integran, por ser sus amigos y por ser solidarios con él, ricos que no se sienten ni superiores ni privilegiados, hay también pobres que por su ambición, por su vanidad, su orgullo y su egoísmo merecen estar fuera del pueblo, porque desprecian a los hombres y mujeres humildes que lo constituyen. (Perón 2012: 313). ${ }^{14}$

Mientras el proletariado está determinado por condiciones económicas, "el pueblo es lo que siente que el pueblo es" (Perón 2012: 314). Esta visión romántica y voluntarista propone una identidad para las clases trabajadoras, construida en torno de la colaboración con un empresariado responsable y un Estado interventor. El peronismo tendría entre sus principales tareas consolidar esa identidad y crear a partir de ella un sentimiento genuino de comunidad:

Nuestro gran trabajo, nuestro trabajo fundamental está en convertir a cada hombre y
a cada mujer en pueblo, o sea, darle a cada uno consciencia de su destino social, con-
ciencia solidaria, pero no agresiva; hacer entender a todos lo que Perón nos ha hecho
entender a los argentinos: que no estamos solos.

(Perón 2012: 315). ${ }^{15}$

La „consciencia del destino social” que cada persona tiene sería esencial en la „comunidad organizada", la respuesta del peronismo a las divisiones y conflictos de la sociedad moderna (Perón 2006). El nuevo mundo que Eva propone incorpora elementos modernos, como la industria y los conflictos entre el empresariado y los trabajadores. Pero también contiene elementos nostálgicos, como las referencias a ,instituciones inviolables” como la familia y la religión o el énfasis en relaciones directas y personales entre la población y sus líderes. De hecho, sería la combinación entre la industria del mundo moderno y el paternalismo del pasado una de las soluciones discursivas más usuales para este dilema.

Esta combinación entre elementos tradicionales y modernos puede observarse también respecto de las mujeres. Como se mencionó más arriba, Eva Perón no escatimó esfuerzo alguno en organizar y conscientizar a la mujer argentina sobre los nuevos roles que estaba llamada a asumir. En este sentido, se podría decir que redefinió la relación entre los géneros: ella no se consideraba "una feminista a la antigua", sino "moderna, que sabe lo que pesan los hombres y lo que pueden aportar las mujeres" colaborando unos con otros (Perón 2012: 98). Pero junto a estos

${ }^{14}$ Discurso pronunciado el 27 de marzo de 1951, en el acto de clausura de la Conferencia Interamericana de Seguridad Social.

${ }^{15}$ Discurso del 27 de marzo de 1951. 
cambios, la "abanderada de los humildes" hace referencia a comportamientos típicamente asociados con la mujer:

Perón necesita del baluarte inviolado del hogar y del impulso intuitivo y sustancialmente conservador de la mujer para llevar adelante y afianzar su programa de acción de gobierno [...] en el centro del país que es tu hogar, y en el centro de tu hogar, que eres tú misma, es alli donde está la realización final del programa de redención politica y social argentina, que Perón inició hace tiempo para el aumento del bienestar en los tuyos. (Perón 2012: 98). ${ }^{16}$

La mujer era considerada por Eva como la depositaria de las mismas funciones que la familia burguesa le había otorgado: ama de casa, madre y esposa. En pocas palabras, ser el principal sostén de un hogar sería su espacio „natural”, en una tensión no explicitada con los roles reconocidos en fábricas y aulas. O con el suyo propio, como líder de la rama femenina del Partido Peronista, líder de una Fundación homónima y combatiente vocera del peronismo. En este sentido, debería tomarse en cuenta que el sentido de los discursos de Eva Perón no se agotaría en lo que ella dijo, con lo problemático que pueda ser definir este contenido. Habría que tomar en cuenta también lo que ella estaba haciendo al decir lo que decía, o los aspectos ilocutivos de su discurso (Skinner 2007: 153-154). Es por eso que no debería subestimarse el carácter rupturista que representaba una mujer cumpliendo esos roles en la sociedad argentina de los años ,40. Si se toma la noción de permotatividad del género de Judith Butler, podría incluso pensarse que Eva habría introducido o por lo menos intensificado prácticas que se generalizarían con el tiempo y contribuirían a redefinir los roles y acciones asociados con el género (Butler 2007:34). ${ }^{17}$ Así, su rol no habría sido menor en la historia de la condición femenina y de las relaciones entre los sexos en la Argentina del siglo XX.

No obstante, esas contradicciones podrían ser vistas también como un reflejo de las dudas de la propia Eva, sometida a los mismos imperativos políticos y ambigüedades que el mismo peronismo. Pero, ¿qué queda de esos discursos más de cincuenta años después de ser pronunciados? ¿No son acaso testimonios de problemas largo tiempo olvidados? ¿A qué se debe su vigencia? ¿Es pura nostalgia de tiempos más "sencillos" o el indicio de que ciertas cuestiones continúan abiertas?

${ }^{16}$ Mensaje pronunciado el 12 de febrero de 1947, por L.R.A. Radio del Estado y la Red Argentina de Radiodifusión, sobre "La mujer argentina y su derecho a elegir y ser elegida".

17 "In this sense, gender is not a noun, but neither is it a set of free-floating attributes, for we have seen that the substantive effect of gender is performatively produced and compelled by the regulatory practices of gender coherence. Hence, within the inherited discourse of the metaphysics of substance, gender proves to be performative - that is, constituting the identity it is purported to be. In this sense, gender is always a doing, though not a doing by a subject who might be said to preexist the deed". 


\section{CONCLUSIÓN. ¿MUNDOS DESAPARECIDOS?}

Estas preguntas no admiten una respuesta sencilla. Los motivos por los cuales se continúa buscando y construyendo un mensaje en torno de los discursos y el símbolo de Eva Perón son diversos y no admiten una explicación unívoca. No obstante, por debajo de la heterogeneidad de las imágenes y los relatos podría encontrarse un denominador común que explicaría su vigencia.

Eva Perón fue, para admiradores y detractores, un personaje central dentro de la historia del peronismo y de la política Argentina. Pero restringirla al marco nacional, considerarla solamente un "fenómeno argentino", puede llevar a malinterpretarla. La protección de niños y ancianos, el cuidado de los humildes, la dignificación de los trabajadores, son problemas que excedieron por mucho a la Argentina. Son desafíos candentes que las sociedades modernas continúan afrontando hasta la actualidad. En los 60 años que transcurrieron desde la muerte de Eva, los ensayos realizados en búsqueda de una mayor equidad social fueron mayormente infructuosos. Es por ese motivo que en los discursos la „leyenda negra” y la „leyenda blanca” de Eva Perón no encuentran solamente las huellas de un mundo desaparecido. Aparece también el mundo actual, dividido por conflictos económicos, políticos y sociales. Por eso, leerlos es una manera de retomar la máxima de Croce y trascenderla: porque se trata de preguntarse por el presente, pero también de transformarlo.

\section{BIBLIOGRAFÍA}

1. Altamirano C. (2011), Peronismo y Cultura de Izquierda, Siglo XXI, Buenos Aires.

2. Angenot M. (2010), El Discurso Social. Los límites históricos de lo pensable y lo decible, Siglo XXI, Buenos Aires.

3. Anguita E. y Caparrós M. (2015) La Voluntad (I). Una historia de la militancia revolucionaria en la Argentina (1966-1973), Planeta, Buenos Aires.

4. Barrancos D. (2008), Mujeres entre la Casa y la Plaza, Sudamericana, Buenos Aires.

5. Ben Plotkin M. (2013), Mañana es San Perón. Propaganda, rituales políticos y educación en el régimen peronista, EDUNTREF, Buenos Aires.

6. Butler J. (2007), Gender Trouble. Feminism and the subversion of identity, Routledge, Nueva York, NY.

7. Belini C. y Korol J.C. (2012), Historia Económica de la Argentina en el Siglo XX, Siglo XXI, Buenos Aires.

8. Croce B. (1942), La Historia como Hazaña de la Libertad, Fondo de Cultura Económica, México.

9. Díaz Alejandro C. (2002), Ensayos sobre la Historia Económica Argentina, Amorrortu, Buenos Aires.

10. Finchelstein F. (2008) La Argentina Fascista. Los origenes ideológicos de la dictadura, Sudamericana, Buenos Aires.

11. Gené M. (2008), Un Mundo Feliz. Imágenes de los trabajadores en el primer peronismo, 1946 1955, Fondo de Cultura Económica, Buenos Aires. 
12. Gillespie R. (2008), Soldados de Perón. Historia crítica sobre Montoneros, Sudamericana, Buenos Aires.

13. Griffin R. (2007) Modernism and Fascism. The Sense of a Beginning under Mussolini and Hitler, Palgrave Macmillan, Nueva York, NY.

14. Klemperer V. (2013) LTI. La lengua del Tercer Reich. Apuntes de un filólogo, Minúscula, Barcelona.

15. Llach L. y Gerchunoff P. (2004) Entre la Equidad y el Crecimiento. Ascenso y caída de la economía argentina, 1880-2002, Siglo XXI, Buenos Aires.

16. Milanesio N. (2014), Cuando los Trabajadores Salieron de Compras. Nuevos consumidores, publicidad y cambio cultural durante el primer peronismo, Siglo XXI, Buenos Aires.

17. Perón E. (2012), Discursos Completos I, Booket, Buenos Aires.

18. Perón E. (2012), Discursos Completos II, Booket, Buenos Aires.

19. Perón J. D. (2006) La Comunidad Organizada, Institucional Nacional „Juan Domingo Perón”, Buenos Aires.

20. Romero J. L. (1959), Las Ideas Políticas en Argentina, Fondo de Cultura Económica, Buenos Aires.

21. Rapoport M. (2012), Historia Económica, Política y Social de la Argentina (1880-2003), Emecé, Buenos Aires.

22. Serge, V. (2002), Memorias de Mundos Desaparecidos (1901-1941), Siglo XXI, México.

23. Skinner, Q. (2007) Lenguaje, Politica e Historia, Universidad Nacional de Quilmes, Quilmes.

24. Torre J. C. (2002), Nueva Historia Argentina (VIII). Los años peronistas (1943-1955), Sudamericana, Buenos Aires.

\title{
„MYTH” AND „LEGEND” OF EVA PERÓN. AN APPROACH THROUGH HER SPEECHES
}

\begin{abstract}
Eva Perón has gained a considerable fame throughout the decades. From key political figure and party sybom, „Evita” has come to be one of the cultural artifacts more closely related to Argentina in a global scale. In that country both the „Lady of Hope” and the movement she belonged to remain a matter of historiographical dispute and, last but not least, a recurrent topic in still ongoing social and political debates. This articles aims to understand in a better way the singular derive of Eva Perón in the discursive and symbolic realms through a brief analysis of the images of her that were formed in the midst of these debates. Finally, it will present a new view on those discussions and on the notoriety of Eva Perón by exploring the ambiguos threads weaved in her public speeches, where feminine liberation, traditional family values and verticalism got along in unstable ways.
\end{abstract}

Key words: Eva Perón, Peronism, Argentina, Cultural History 